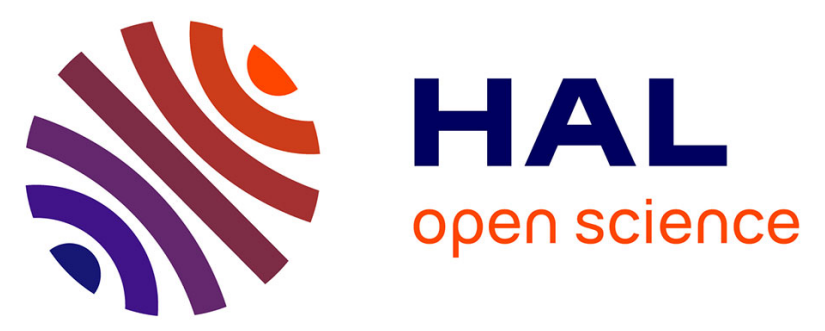

\title{
Phase 1 trial of ralimetinib (LY2228820) with radiotherapy plus concomitant temozolomide in the treatment of newly diagnosed glioblastoma
}

J. Biau, E. Thivat, E. Chautard, D. Stefan, Mathieu Boone, Bruno Chauffert, C. Bourgne, D. Richard, I. Molna, S. Levesque, et al.

\section{To cite this version:}

J. Biau, E. Thivat, E. Chautard, D. Stefan, Mathieu Boone, et al.. Phase 1 trial of ralimetinib (LY2228820) with radiotherapy plus concomitant temozolomide in the treatment of newly diagnosed glioblastoma. Radiotherapy \& Oncology, 2021, 154 (227-234), 10.1016/j.radonc.2020.09.036 . hal02954534

\section{HAL Id: hal-02954534 \\ https://hal.science/hal-02954534}

Submitted on 5 Nov 2020

HAL is a multi-disciplinary open access archive for the deposit and dissemination of scientific research documents, whether they are published or not. The documents may come from teaching and research institutions in France or abroad, or from public or private research centers.
L'archive ouverte pluridisciplinaire HAL, est destinée au dépôt et à la diffusion de documents scientifiques de niveau recherche, publiés ou non, émanant des établissements d'enseignement et de recherche français ou étrangers, des laboratoires publics ou privés.

\section{()ㅜ) $\Theta$}

Distributed under a Creative Commons Attribution - NoDerivatives| 4.0 International 


\section{Phase 1 trial of ralimetinib (LY2228820) with radiotherapy plus concomitant temozolomide in the treatment of newly diagnosed glioblastoma}

J Biau ${ }^{\text {a,b,c }}$, E Thivat ${ }^{\text {b,c,d }}$, E Chautard ${ }^{\text {b,e }}$, D Stefan ${ }^{\mathrm{f}}$, M Boone ${ }^{\mathrm{g}}$, B. Chauffert ${ }^{\mathrm{g}}$, C Bourgne ${ }^{\mathrm{h}}$, D Richard ${ }^{\mathrm{i}}$, I Molnar ${ }^{\mathrm{b}, \mathrm{c}, \mathrm{d}}, \mathrm{S}$ Levesque $^{\mathrm{b}, \mathrm{c}, \mathrm{d}}, \mathrm{R}$ Bellini ${ }^{\mathrm{j}}$, F Kwiatkowski ${ }^{\mathrm{b}, \mathrm{c}, \mathrm{d}}$, L Karayan-Tapon $^{\mathrm{k}}$, P. Verrelle ${ }^{\mathrm{a}, \mathrm{l}}$, C Godfraind $^{\mathrm{m}}, \mathrm{X}$ Durando ${ }^{\mathrm{b}, \mathrm{c}, \mathrm{d}, \mathrm{n}}$

${ }^{\text {a }}$ Radiation department, Centre Jean Perrin, Clermont-Ferrand, F-63011 France; University of Clermont Auvergne, UFR Médecine, Clermont-Ferrand

${ }^{\mathrm{b}}$ INSERM U1240 IMoST, University of Clermont Auvergne, Clermont-Ferrand, FR-63000, France

${ }^{\mathrm{c}}$ Centre d'Investigation Clinique UMR 501, Clermont-Ferrand, F-63001 France

${ }^{\mathrm{d}}$ Department of clinical research, Délégation Recherche Clinique et Innovation, Centre Jean Perrin, F63011 Clermont-Ferrand, France

${ }^{\mathrm{e}}$ Pathology department, Centre Jean Perrin, Clermont-Ferrand, France. F-63011 France

${ }^{\mathrm{f}}$ Radiation oncology department, Centre François Baclesse, F-14076, Caen, France

${ }^{\mathrm{g}}$ Department of Medical oncology, CHU Amiens, 80054, Amiens Cedex 1, France

${ }^{\mathrm{h}}$ Department of Biologic hematology, CHU Estaing, 63003 Clermont-Ferrand Cedex 1, France

${ }^{i}$ CHU Clermont-Ferrand, University of Clermont-Auvergne, Medical Pharmacology department, UMR INSERM, 1107 Neuro-Dol, F-63000, Clermont-Ferrand, France

${ }^{j}$ Radiodiagnostic Department, Centre Jean-Perrin, Clermont-Ferrand, France. F-63011 France

${ }^{\mathrm{k}}$ University of Poitiers, INSERMU1084, CHU de Poitiers, Department of Cancer Biology, 86021 Poitiers, France

${ }^{1}$ Department of Radiation Oncology, Institut Curie, Paris, France

${ }^{\mathrm{m}}$ Department of Pathological Anatomy, CHU de Clermont-Ferrand, Clermont-Ferrand, France

${ }^{\mathrm{n}}$ Oncology Department, Centre Jean Perrin, Clermont-Ferrand, F-63011 France; University of Clermont Auvergne, UFR Médecine, Clermont-Ferrand

Corresponding author: Julian Biau

Centre Jean Perrin, 58 rue Montalembert, 63011 Clermont-Ferrand, France

E-mail address: julian.biau@clermont.unicancer.fr 


\section{Abstract (250 words):}

Background and purpose: This phase 1 trial aimed to determine the maximum tolerated dose (MTD; primary objective) of a p38-MAPK inhibitor, ralimetinib, with radiotherapy (RT) and chemotherapy (TMZ), in the treatment of newly diagnosed glioblastoma (GBM) patients.

Materials and methods: The study was designed as an open-label dose-escalation study driven by a TiteCRM design and followed by an expansion cohort. Ralimetinib was administered orally every 12 hours, 7 days a week, for 2 cycles of 2 weeks at a dose of 100, 200 or $300 \mathrm{mg} / 12 \mathrm{~h}$. Patients received ralimetinib added to standard concurrent RT (60 Gy in 30 fractions) with TMZ (75 mg/m²/day) and 6 cycles of adjuvant TMZ ( 150 to $200 \mathrm{mg} / \mathrm{m}^{2}$ on days 1 to 5 every 28 days).

Results: The MTD of ralimetinib was $100 \mathrm{mg} / 12 \mathrm{~h}$ with chemoradiotherapy. The three patients treated at $200 \mathrm{mg} / 12 \mathrm{~h}$ presented a dose-limiting toxicity: one patient had a grade 3 face edema, and two patients had a grade 3 rash and grade 3 hepatic cytolysis (66\%). Of the 18 enrolled patients, 15 received the MTD of ralimetinib. At the MTD, the grade $\geq 3$ adverse events during concomitant chemoradiotherapy were hepatic cytolysis (2/15 patients), dermatitis/rash (1/15), lymphopenia (1/15) and nausea/vomiting (1/15). No interaction of TMZ and ralimetinib when administrated concomitantly has been observed. Inhibition of pMAPKAP-K2 (-54\%) was observed in peripheral blood mononuclear cells.

Conclusion: This phase 1 trial is the first trial to study the combination of a p38-MAPK inhibitor, ralimetinib, with radiotherapy (RT) and chemotherapy (TMZ), in the treatment of newly diagnosed glioblastoma (GBM) patients. The MTD of ralimetinib was $100 \mathrm{mg} / 12 \mathrm{~h}$. The most frequent doselimiting toxicities were hepatic cytolysis and rash.

Keywords: ralimetinib, radiotherapy, temozolomide, glioblastoma, phase I clinical trial 


\section{Introduction}

Glioblastoma (GBM) is the most common and aggressive adult primary brain tumor $[1,2]$. Although radiotherapy (RT) with concomitant and adjuvant temozolomide (TMZ) has increased patient survival, long-term prognosis remains poor, with a median survival of 15 months [3, 4]. Tumor progression most often occurs inside the irradiated tumor volume [5], showing the high radioresistance of these tumors. Mitogen-activated protein kinase (MAPK) cascades are key signaling pathways involved in the regulation of cell proliferation, survival and differentiation. Activation of p38-MAPK has been associated with a poor prognosis in GBM [6]. P38-MAPK activation represents a compensatory response by tumor cells to environmental stressors such as RT and chemotherapy [7, 8]. Therefore, combining the current treatment of GBM with p38-MAPK inhibition represents a promising opportunity.

Ralimetinib (LY2228820), a selective inhibitor of $\alpha$ - and $\beta$-isoforms of p38-MAPK, reduces phosphorylation of its cellular direct target, MAPK-activated protein kinase 2 (MAPKAP-K2). Preclinical studies demonstrated that ralimetinib had antitumor activity [9] and enhanced sensitivity to TMZ in GBM xenograft models [10]. Ralimetinib has also been tested in different phase 1 or 2 clinical trials alone or combined with hormono/chemotherapy [11-13]. However, before this study, no clinical trials had tested ralimetinib in combination with $\mathrm{RT} \pm$ chemotherapy.

Here, we report the results of the first phase 1 trial to evaluate the combination of ralimetinib (a p38-MAPK inhibitor) with RT and chemotherapy (TMZ) in the treatment of newly diagnosed GBM. The primary objective was to determine the recommended dose of ralimetinib in combination with TMZ and RT. The secondary objectives were to characterize the pharmacokinetics drug-drug interaction and impact of ralimetinib on MAPKAP-K2 activation in peripheral blood mononuclear cells (PBMC). 


\section{Materials and Methods}

\section{Patients}

Eligible patients were 18 to 75 years of age with newly diagnosed and histologically confirmed GBM, with a recursive partitioning analysis (RPA) of class III or IV [14], and adequate hematologic and hepatic function. Patients receiving corticosteroids were eligible if they received a stable or decreasing dose for at least 14 days before enrollment.

Patients with a history of other malignancy within 5 years prior to enrollment, diagnosis of inflammatory bowel disease, diarrhea of any cause $\geq$ CTCAE grade 2, a major bowel resection that would alter oral drug absorption, and/or concurrent administration of immunosuppressive therapy were excluded. All patients provided written informed consent prior to enrollment.

\section{Study design and treatment plan}

The study was approved by the ethics committee and the national regulator and registered with www.clinicaltrials.gov (NCT02364206).

This phase I study was an open-label, multicenter dose-escalation study with an expansion cohort. The dose escalation was driven by a Tite-CRM (Time to event Continual Reassessment Method) [15] method with 3 ralimetinib dose levels. Cohorts of 3 to 6 patients were treated, with a minimum of 6 patients at the recommended dose.

Ralimetinib. Ralimetinib was given orally every 12 hours, 7 days a week, for 2 cycles of 2 weeks [11] (Figure 1), at 100 (dose 1), 200 (dose 2) or $300 \mathrm{mg} / 12 \mathrm{~h}$ (dose3). The first cycle started one week before the beginning of RT and the second during the $4^{\text {th }}$ and $5^{\text {th }}$ weeks of RT.

Radiotherapy. For irradiation, all patients were immobilized with custom thermoplastic masks. Target volume and organs at risk delineation was done by a dedicated CT-scan in the treatment position matched and fused with contrast-enhanced T1-weighted and Flair MRI sequences. The gross tumor volume (GTV) was defined as the contrast enhancement area in the T1-weighted MRI sequence, including the tumor bed for patients with partial or complete resection. The clinical target volume (CTV) was defined as the addition of a geometric tridimensional $1-\mathrm{cm}$ margin around the GTV that was 
corrected to the anatomical borders. The CTV also included hyperintensity in the Flair MRI sequence. The planning target volume (PTV) was defined as the addition of a geometric tridimensional 4-mm margin around the CTV. RT consisting of fractionated focal irradiation at a dose of 2 Gy per fraction was given once daily five days per week over a period of 6 weeks, for a total dose of 60 Gy. Threedimensional conformal RT and Intensity-Modulated RT (IMRT) were allowed.

Temozolomide: Concomitant TMZ at a dose of $75 \mathrm{mg} / \mathrm{m}^{2}$ per day was given 7 days per week from the first day of RT until the end of RT. Four weeks after RT, patients received a maximum of 6 cycles of adjuvant TMZ according to the standard 5-day schedule every 28 days (at a dose of $150 \mathrm{mg} / \mathrm{m}^{2} / \mathrm{day}$ for the first cycle and then at $200 \mathrm{mg} / \mathrm{m}^{2} /$ day in the absence of toxicity).

\section{Patient evaluation}

Toxicity was graded according to the National Cancer Institute's Common Toxicity Criteria version 4.03 (NCI-CTCAE v4.03). The neurologic status of patients was evaluated by clinical assessment and Mini-Mental State Examination (MMSE) and evaluation of corticoid dosage.

Disease evaluations were based on RANO criteria (Response Assessment in Neuro-Oncology) [16]. Magnetic Resonance Imaging (MRI) was performed within 28 days before the initiation of the study treatment, 4 weeks after the end of RT, every 8 weeks during the adjuvant period, and subsequently every 3 months during the first 2 years.

\section{Biomarkers assessment}

A central pathology review and biomarker assessment has been implemented on FFPE blocks used for diagnosis. ATRX, PTEN protein scoring, CD34, IDH1 R132H mutation, and pMAPKAPK-2 were detected by immunohistochemistry. MGMT promoter methylation was performed by a pyrosequencing methylation assay $[17,18]$.

\section{Pharmacokinetic assay}

Ralimetinib and TMZ concentrations were determined by a multiparameter method using a liquid chromatography/tandem mass spectrometry assay. Whole blood samples were collected on days 
(D) 7 (ralimetinib), 28 (TMZ) and 35 (ralimetinib and TMZ) with a 10-point kinetic analysis at 10h

(Figure 1). Pharmacokinetic analyses included the area under the plasma concentration/time curve to the last sampling time point (AUC), peak observed concentration (Cmax), and time to Cmax (Tmax).

To explore the passage of ralimetinib across the blood-brain barrier, an optional substudy was proposed with a ralimetinib dosage in cerebrospinal fluid 7 days after administration.

\section{Pharmacodynamic assay}

The pharmacodynamic of ralimetinib was explored through the assessment of pMAPKAP-K2 on anisomycin-stimulated PBMC by flow cytometry. Pharmacodynamic analyses were conducted on plasma samples collected at the predose on D1, and after treatment administration on D7 (ralimetinib), D28 (TMZ), D35 (ralimetinib and TMZ) (Figure 1).

\section{Statistical considerations}

The recommended dose was the maximum tolerated dose (MTD) of ralimetinib. The MTD was defined as the highest dose tested in which a dose-limiting toxicity (DLT) was experienced by no more than $33 \%$ of patients. DLT was defined as any grade 3-4 toxicity except alopecia, nausea, and vomiting which can be rapidly controlled with appropriate measures. Only toxicities occurring between the first day of ralimetinib until 2 weeks after the end of RT were considered for DLT assessment.

Due to the exploratory nature of the current study and the relatively low number of patients, mainly descriptive statistics were used. The safety population consisted of all patients who received any dose of ralimetinib.

Progression-free survival (PFS) and overall survival (OS) were measured from study enrollment. PFS and OS curves and estimates were constructed using the Kaplan-Meier method. Predictive factors of PFS were investigated using univariate Cox regressions and a multivariate model including parameters with $\mathrm{p}<.25$ in the univariate analysis.

Comparisons of pharmacokinetic and pharmacodynamic parameters at different times and doses were assessed by paired t-test, Welch's t-test or Wilcoxon's rank test (depending on the distribution of 
data and without multiple-comparisons correction due to the exploratory nature of the analysis and very small sample size).

The statistical significance threshold was set at 5\%. Statistical analyses were performed using R software. 


\section{Results}

Between June 2015 and December 2016, 9 patients were enrolled in the phase 1 study (cohort 1 at dose 1: $\mathrm{n}=6$; cohort 2 at dose 2: $\mathrm{n}=3$ ); and 9 patients in the expansion cohort dose 1). Patient characteristics at baseline are presented in Table 1. All enrolled patients received at least one dose of ralimetinib: 15 received ralimetinib at $100 \mathrm{mg} / 12 \mathrm{~h}$ and 3 at $200 \mathrm{mg} / 12 \mathrm{~h} .15$ completed the 2 cycles of ralimetinib through radiochemotherapy and 15 completed the 6 cycles of adjuvant TMZ. A dose reduction of ralimetinib (between cycles) was implemented for 2 patients (treated at $200 \mathrm{mg}$ ) due to toxicity. In addition, six patients interrupted ralimetinib treatment due to toxicity ( $\mathrm{n}=4: 2$ for each dose), the patient's decision $(n=1)$ and non-respect of the treatment schedule $(n=1)$. This last patient was withdrawn from the study for non-compliance with the administration schedule (without concomitant administration of ralimetinib with chemoradiotherapy due to RT offset for technical reasons) but was evaluated for safety. One patient treated at $200 \mathrm{mg} / 12 \mathrm{~h}$ permanently discontinued ralimetinib treatment for toxicity.

In the Phase 1 part, none of the first 3 patients treated at dose 1 had a DLT, allowing for dose 2 assessment. The three patients treated at $200 \mathrm{mg} / 12 \mathrm{~h}$ presented a DLT: one patient had a grade 3 face edema, and two patients had a grade 3 rash and grade 3 hepatic cytolysis (Table 2). According to study design, 3 more patients were treated at dose 1. Of these three patients, only one patient presented a DLT consisting of grade 3 lymphopenia. None of the DLT was related with RT. All these DLT were reversible with appropriate measures. The MTD of ralimetinib was then considered to be $100 \mathrm{mg} / 12 \mathrm{~h}$ (dose 1 ) and was used in the expansion cohort. Three of the 9 patients of the expansion cohort presented a DLT: 2 had hepatic cytolysis ( 1 of grade 3, another of grade 4 with cholestasis, and 1 with a rash (grade 3 ). Among the 15 patients (6 in phase 1 and 9 in the expansion cohort) treated at $100 \mathrm{mg} / 12 \mathrm{~h}$, DLT occurred in a total of 4 patients (27\%) which confirmed the recommended dose of $100 \mathrm{mg} / 12 \mathrm{~h}$.

Overall, the most common adverse events (AE) (all grades and for the entire study period) were asthenia (78\%), nausea/vomiting (72\%), dermatitis/rash (61\%), headache (61\%), constipation (44\%), hepatic cytolysis (44\%), and alopecia (39\%) (Table 3). Twelve patients experienced one or more severe 
(grade $\geq 3) \mathrm{AE}(67 \%)$. The most frequently severe $\mathrm{AE}$ for the entire study period were dermatitis/rash in $22 \%$ (4/18), hepatic cytolysis in $22 \%$ (4/18), and lymphopenia in $11 \%(2 / 18)$ of patients. Considering only patients treated at the recommended dose of $100 \mathrm{mg}$, severe AE were observed in 5 patients during the concomitant period (33\%): hepatic cytolysis in 13\% (2/15), cholestasis in 7\% (1/15), dermatitis/rash in $7 \%(1 / 15)$, lymphopenia in $7 \%(1 / 15)$, and nausea/vomiting in $7 \%$ of patients $(1 / 15)$. No death related to treatment was reported. No patient presented a grade $\geq 3$ radio-induced toxicity.

Concerning pharmacokinetic, mean Cmax after ralimetinib alone at $100 \mathrm{mg} / 12 \mathrm{~h}$ was $300 \pm 64$ $\mathrm{ng} / \mathrm{mL}$ vs $827 \pm 144 \mathrm{ng} / \mathrm{mL}$ at $200 \mathrm{mg} / 12 \mathrm{~h}\left(\mathrm{p}=0.048\right.$ ) (Figure 2). Mean $\mathrm{AUC}_{0-10}$ after ralimetinib alone at $100 \mathrm{mg} / 12 \mathrm{~h}$ was $1725 \pm 292 \mathrm{ng} . \mathrm{h} / \mathrm{mL}$ vs $3598 \pm 673 \mathrm{ng} . \mathrm{h} / \mathrm{mL}$ at $200 \mathrm{mg} / 12 \mathrm{~h}$ (p=0.09). Tmax was not significantly different between both doses. No interaction of TMZ and ralimetinib when administrated concomitantly has been noted, just as no significant differences have been observed in Cmax, Tmax and AUC for both drugs when administrated concomitantly than when administrated alone (ralimetinib: D7 vs D35; TMZ: D28 vs D35), but the study is under-powered for this type of analysis (supplementary data). Patient No. 8 presented an accumulation of 2 molecules ralimetinib and TMZ at D35. One patient treated at $100 \mathrm{mg} / 12 \mathrm{~h}$ had cerebral fluid detection of ralimetinib. Ralimetinib dosage was $29 \mathrm{ng} / \mathrm{mL}$ in cerebral fluid vs $125 \mathrm{ng} / \mathrm{ml}$ in plasma at the same time (180 min post administration). Concerning pharmacodynamic, as shown in Figure 3, ralimetinib induced a strong inhibition of pMAPKAP-K2 (54\%) in PBMC as early as 1 hour after the first oral intake. A similar effect was observed on D7 (52\%) and D35 (56\%) with TMZ. The results obtained for one patient at $200 \mathrm{mg}$ were very close to those observed at $100 \mathrm{mg}$ and were therefore pooled to present the data (on average $62 \%$ ).

We reported the efficacy outcomes of the 15 patients treated at the recommended dose (100 $\mathrm{mg} / 12 \mathrm{~h}$ ). At the last follow-up (median of 41.4 months), 10/15 patients had a progression and 9/15 were dead. The 6-month, 1-year, and 2-year PFS rates were, respectively, 92.9\% (95\% CI [80-100]), 50\% (95\% CI [29-85]), and 35.7\% (5\% CI [17-73]). The median PFS was 12.8 months IC95 (7.9 lower boundary of $95 \% \mathrm{CI}$ ), whereas the median overall survival was 24.5 months (16.5 lower boundary of 95\% CI). In multivariate analysis, we found a link between the IDH1 mutation and a better prognosis 
(HR of 0.116 ; $95 \%$ CI, $0.014-0.995$ for PFS), as widely described, in addition to an association between PTEN expression in the tumour and a poorer prognosis (HR of 10.5; 95\%CI, 1.12-10.5 for PFS). 


\section{Discussion}

Our trial was the first to evaluate the combination of ralimetinib, a p38-MAPK inhibitor, with RT and TMZ in the treatment of newly diagnosed GBM. We met our primary objective with a recommended dose $(\mathrm{RD})$ of ralimetinib at $100 \mathrm{mg} / 12 \mathrm{~h}$.

This dose was lower than the RD of ralimetinib determined in previous phase I trials. In the first phase I study in advanced cancer, the RD was $300 \mathrm{mg} / 12 \mathrm{~h} \mathrm{[11]} \mathrm{as} \mathrm{monotherapy} \mathrm{or} \mathrm{with} \mathrm{tamoxifen.} \mathrm{In} \mathrm{a}$ randomized phase $\mathrm{Ib} / \mathrm{II}$ test on the combination of gemcitabine and carboplatine $+/$ - ralimetinib for women with ovarian cancer, the RD was $200 \mathrm{mg} / 12 \mathrm{~h}$ (D1-10 q21d) [12]. Another phase I study assessing the combination of ralimetinib with prexasertib (checkpoint kinase 1 inhibitor) in patients with advanced or metastatic cancer [13] did not succeed in establishing a RD of ralimetinib. With a model-based 3+3 dose escalation, no DLT was observed in the cohort of 3 patients treated at $100 \mathrm{mg} / 12 \mathrm{~h}$, though 3/6 patients experienced DLT at a dose of $200 \mathrm{mg} / 12 \mathrm{~h}$ (D1 to 14).

In the current trial, DLTs were consistent with the known toxicities of ralimetinib (asthenia, nausea, rash, constipation, vomiting, pruritus and hepatic cytolysis) and well-established side effects of RT and TMZ. All patients treated at $200 \mathrm{mg} / 12 \mathrm{~h}$ experienced a grade 3 rash (/edema) and only one (7\%) at 100 $\mathrm{mg} / 12 \mathrm{~h}$ with a $9 \%$ grade $\geq 3 \mathrm{rash}$, as described in the first ralimetinib phase 1 trial [11]. One patient (treated at $100 \mathrm{mg} / 12 \mathrm{~h}$ ) had grade 3 lymphopenia. Even if this toxicity is well established with TMZ [3, 4], it has also been described with ramelitinib [11]. Four patients (22\%) experienced grade $\geq 3$ hepatic cytolysis during concomitant period (all resolved after stopping ralimetinib and TMZ, allowing restarting of TMZ and TMZ maintenance). Hepatic cytolysis has been recently observed in conjunction with ralimetinib use and was also a potential side effect of TMZ, with up to $26 \%$ grade 3 enzyme elevations associated with TMZ in GBM patients [19-24]. Other series have reported fewer rates of liver enzyme elevation [19-23]. Also, several cases of severe cholestatic hepatitis have been reported [25-28] with the onset of injury within 1 to 7 months of starting TMZ. In the randomized double-blind placebo-controlled phase Ib/II study of gemcitabine and carboplatin $+/$ - ralimetinib in recurrent ovarian cancer, grade 3-4 elevated alanine aminotransferase was more frequent in the ralimetinib arm (19.7\% 
vs $3.8 \%$ ) [12]. In our study, the occurrence of grade 3 hepatic cytolysis on 2 patients (66\%) treated at $200 \mathrm{mg} / 12 \mathrm{~h}$, with one at D14 (7 days after TMZ start) raises the question of a potential increased liver toxicity with ralimetinib and TMZ. However, among the 15 patients treated at $100 \mathrm{mg} / 12 \mathrm{~h}$, only $13 \%$ experienced severe hepatic cytolysis, both rapidly reversible with appropriate measures. Nevertheless, appropriate liver monitoring seems essential in future trials, especially as TMZ might also induce sever hepatotoxicity. No severe toxicity related to RT was reported, demonstrating that ralimetinib was well tolerated in combination with RT.

Despite the small number of patients, the PK parameters were in accordance with previous PK analysis of ralimetinib monotherapy [11]. No evidence of significant drug-drug interaction between ralimetinib and TMZ has been highlighted. One patient presented an accumulation of ralimetinib and $\mathrm{TMZ}$ at D35, attesting to an idiosyncratic metabolic problem. While UGT enzymes were involved in the metabolic clearance of ralimetinib, the genotype of UGT1A1*1/*1 and UGT1A4*1a/*1b of this patient, with a usual glucoroconjugation capacity, does not explain the observed accumulation.

In our study, ralimetinib administrated at $100 \mathrm{mg} / 12 \mathrm{~h}$ demonstrated a pharmacodynamic response with a significant inhibition of pMAPKAP-K2 in PBMC of around 50-60\% as observed with a $300 \mathrm{mg} / 12 \mathrm{~h}$ dose [11]. A critical issue in brain tumor therapy is whether the drug penetrates the blood-brain barrier to reach the target. Dosage of ralimetinib in the cerebral fluid was possible for only one patient, but it showed that ralimetinib could go across the BBB with a favorable ratio of approximately $24 \%$ (vs blood). Further studies would be needed to determine the pharmacodynamic response of ralimetinib within the tumor and tumor microenvironment; however, technical issues in obtaining GBM biopsies create limitations.

The small sample size of the expansion cohort with a total of 15 patients treated at the RD of ralimetinib represents an important limitation of these data. The planned phase II trial $(n=40)$ was discontinued due to an industry decision to stop providing ralimetinib before the end of recruitment. However, the first results of the efficacy of the association of a p38-MAPK inhibitor alongside RT and TMZ for the treatment of GBM were encouraging, with a PFS rate at 6 months of 93\%, a PFS of 12.6 
months and a OS of 24.5 months compared with historical data of the standard of care [3,4]. These results should be interpreted with caution, taking into account the high percent of IDH-1 mutant GBM (27\%) and of MGMT methylated patients (31\% of known methylation status). Future randomized trials are needed to evaluate the efficacy of ralimetinib in combination with chemoradiotherapy in GBM.

These results represent the first proof-of-concept study to report the outcomes of a p38-MAPK inhibitor with RT and chemotherapy in newly diagnosed GBM. Another p38-inhibitor compound, LY3007113, has been tested in advanced cancer patients. Further development is not planned because its toxicity, which produced symptoms such as tremors and rashes, precluded achieving a biologically effective dose [43]. Grade $\geq 3$ treatment-related adverse events included upper gastrointestinal hemorrhage and increased hepatic enzyme. SCIO-469 (Talmapimod), BIRB-796 (Doramapimod) and Losmapimod have shown interesting anti-tumoral activity in preclinical models of multiple myeloma [29-31] [32], epidermoid carcinoma [33] and cervical cancer [34] or NSCLC (PDX mouse model) [35]. So far, however, its administration in men has only been tested in the field of anti-inflammatory research [36] or in patients with myelodysplastic syndrome [37], post-myocardial infarction [38], or facioscapulohumeral muscular dystrophy (recent orphan drug status of losmapimod by FDA).

This phase I trial showed that combining ralimetinib with standard chemoradiation for newly diagnosed GBM was feasible. The most frequent and critical dose-limiting toxicity was hepatic cytolysis. The MTD of ralimetinib was determined at $100 \mathrm{mg} / 12 \mathrm{~h}$. These results represent the first proofof-concept of an association of a p38-MAPK inhibitor with RT and chemotherapy justifying further randomized trials. 


\section{Acknowledgement}

This study was supported by INCa (Institut National du Cancer) and the foundation ARC. Ralimetinib was provided by Eli Lilly and Company. The authors would like to thank Xavier Paoletti of the Department of Biostatistics at the Institut Curie for providing statistical assistance for the Tite-CRM Method. 


\section{References}

1. Ricard D, Idbaih A, Ducray F, et al (2012) Primary brain tumours in adults. Lancet 379:1984-1996. https://doi.org/10.1016/S0140-6736(11)61346-9

2. Louis DN, Perry A, Reifenberger G, et al (2016) The 2016 World Health Organization Classification of Tumors of the Central Nervous System: a summary. Acta Neuropathol (Berl) 131:803-820. https://doi.org/10.1007/s00401-016-1545-1

3. Stupp R, Mason WP, van den Bent MJ, et al (2005) Radiotherapy plus concomitant and adjuvant temozolomide for glioblastoma. N Engl J Med 352:987-996.

https://doi.org/10.1056/NEJMoa043330

4. Stupp R, Hegi ME, Mason WP, et al (2009) Effects of radiotherapy with concomitant and adjuvant temozolomide versus radiotherapy alone on survival in glioblastoma in a randomised phase III study: 5-year analysis of the EORTC-NCIC trial. Lancet Oncol 10:459-466.

https://doi.org/10.1016/S1470-2045(09)70025-7

5. Bleehen NM, Stenning SP (1991) A Medical Research Council trial of two radiotherapy doses in the treatment of grades 3 and 4 astrocytoma. The Medical Research Council Brain Tumour Working Party. Br J Cancer 64:769-774

6. Patil CG, Nuño M, Elramsisy A, et al (2013) High levels of phosphorylated MAP kinase are associated with poor survival among patients with glioblastoma during the temozolomide era. Neuro-Oncol 15:104-111. https://doi.org/10.1093/neuonc/nos272

7. Hideshima T, Akiyama M, Hayashi T, et al (2003) Targeting p38 MAPK inhibits multiple myeloma cell growth in the bone marrow milieu. Blood 101:703-705. https://doi.org/10.1182/blood2002-06-1874

8. Hideshima T, Podar K, Chauhan D, et al (2004) p38 MAPK inhibition enhances PS-341 (bortezomib)-induced cytotoxicity against multiple myeloma cells. Oncogene 23:8766-8776. https://doi.org/10.1038/sj.onc.1208118

9. Campbell RM, Anderson BD, Brooks NA, et al (2014) Characterization of LY2228820 dimesylate, a potent and selective inhibitor of p38 MAPK with antitumor activity. Mol Cancer Ther 13:364374. https://doi.org/10.1158/1535-7163.MCT-13-0513

10. Starling J, Campbell R, Shih C, et al (2006) P38 MAPK inhibitor, LY2228820, causes significant chemopotentiation of temozolomide in U87MG human glioblastoma xenografts. Cancer Res 66:575-575

11. Patnaik A, Haluska P, Tolcher AW, et al (2016) A First-in-Human Phase I Study of the Oral p38 MAPK Inhibitor, Ralimetinib (LY2228820 Dimesylate), in Patients with Advanced Cancer. Clin Cancer Res Off J Am Assoc Cancer Res 22:1095-1102. https://doi.org/10.1158/1078-0432.CCR15-1718

12. Vergote I, Heitz F, Buderath $P$, et al (2020) A randomized, double-blind, placebo-controlled phase $1 \mathrm{~b} / 2$ study of ralimetinib, a p38 MAPK inhibitor, plus gemcitabine and carboplatin versus gemcitabine and carboplatin for women with recurrent platinum-sensitive ovarian cancer. Gynecol Oncol 156:23-31. https://doi.org/10.1016/j.ygyno.2019.11.006 
13. Bendell JC, Bischoff HG, Hwang J, et al (2019) A phase 1 dose-escalation study of checkpoint kinase 1 (CHK1) inhibitor prexasertib in combination with p38 mitogen-activated protein kinase (p38 MAPK) inhibitor ralimetinib in patients with advanced or metastatic cancer. Invest New Drugs. https://doi.org/10.1007/s10637-019-00873-6

14. Li J, Wang M, Won M, et al (2011) Validation and simplification of the Radiation Therapy Oncology Group recursive partitioning analysis classification for glioblastoma. Int J Radiat Oncol Biol Phys 81:623-630. https://doi.org/10.1016/j.ijrobp.2010.06.012

15. Cheung YK, Chappell R (2000) Sequential designs for phase I clinical trials with late-onset toxicities. Biometrics 56:1177-1182

16. Wen PY, Macdonald DR, Reardon DA, et al (2010) Updated response assessment criteria for highgrade gliomas: response assessment in neuro-oncology working group. J Clin Oncol Off J Am Soc Clin Oncol 28:1963-1972. https://doi.org/10.1200/JCO.2009.26.3541

17. Villalva C, Cortes U, Wager M, et al (2012) O6-Methylguanine-methyltransferase (MGMT) promoter methylation status in glioma stem-like cells is correlated to temozolomide sensitivity under differentiation-promoting conditions. Int J Mol Sci 13:6983-6994.

https://doi.org/10.3390/ijms13066983

18. McDonald KL, Rapkins RW, Olivier J, et al (2013) The T genotype of the MGMT C>T ( $r$ 16906252) enhancer single-nucleotide polymorphism (SNP) is associated with promoter methylation and longer survival in glioblastoma patients. Eur J Cancer Oxf Engl 1990 49:360-368. https://doi.org/10.1016/j.ejca.2012.08.012

19. Clarke JL, Iwamoto FM, Sul J, et al (2009) Randomized phase II trial of chemoradiotherapy followed by either dose-dense or metronomic temozolomide for newly diagnosed glioblastoma. J Clin Oncol Off J Am Soc Clin Oncol 27:3861-3867. https://doi.org/10.1200/JCO.2008.20.7944

20. Yang S-H, Kim M-K, Lee T-K, et al (2006) Temozolomide chemotherapy in patients with recurrent malignant gliomas. J Korean Med Sci 21:739-744. https://doi.org/10.3346/jkms.2006.21.4.739

21. Gállego Pérez-Larraya J, Ducray F, Chinot O, et al (2011) Temozolomide in elderly patients with newly diagnosed glioblastoma and poor performance status: an ANOCEF phase II trial. J Clin Oncol Off J Am Soc Clin Oncol 29:3050-3055. https://doi.org/10.1200/JCO.2011.34.8086

22. Dixit S, Baker L, Walmsley V, Hingorani M (2012) Temozolomide-related idiosyncratic and other uncommon toxicities: a systematic review. Anticancer Drugs 23:1099-1106. https://doi.org/10.1097/CAD.0b013e328356f5b0

23. Niewald M, Berdel C, Fleckenstein J, et al (2011) Toxicity after radiochemotherapy for glioblastoma using temozolomide--a retrospective evaluation. Radiat Oncol Lond Engl 6:141. https://doi.org/10.1186/1748-717X-6-141

24. Wick W, Platten M, Meisner C, et al (2012) Temozolomide chemotherapy alone versus radiotherapy alone for malignant astrocytoma in the elderly: the NOA-08 randomised, phase 3 trial. Lancet Oncol 13:707-715. https://doi.org/10.1016/S1470-2045(12)70164-X

25. Grewal J, Dellinger CA, Yung WKA (2007) Fatal reactivation of hepatitis B with temozolomide. N Engl J Med 356:1591-1592. https://doi.org/10.1056/NEJMc063696 
26. Goldbecker A, Tryc AB, Raab P, et al (2011) Hepatic encephalopathy after treatment with temozolomide. J Neurooncol 103:163-166. https://doi.org/10.1007/s11060-010-0354-y

27. Sarganas G, Orzechowski HD, Klimpel A, et al (2012) Severe sustained cholestatic hepatitis following temozolomide in a patient with glioblastoma multiforme: case study and review of data from the FDA adverse event reporting system. Neuro-Oncol 14:541-546. https://doi.org/10.1093/neuonc/nos056

28. Dixit S, Hingorani M, Afzal P, Campbell AP (2011) Temozolomide induced liver injury. Acta Neurol Belg 111:249-251

29. Hideshima T, Podar K, Chauhan D, et al (2004) p38 MAPK inhibition enhances PS-341 (bortezomib)-induced cytotoxicity against multiple myeloma cells. Oncogene 23:8766-8776. https://doi.org/10.1038/sj.onc.1208118

30. Navas TA, Nguyen AN, Hideshima T, et al (2006) Inhibition of p38alpha MAPK enhances proteasome inhibitor-induced apoptosis of myeloma cells by modulating $\mathrm{Hsp27,} \mathrm{Bcl-X(L),} \mathrm{Mcl-1}$ and p53 levels in vitro and inhibits tumor growth in vivo. Leukemia 20:1017-1027. https://doi.org/10.1038/sj.leu.2404200

31. Vanderkerken K, Medicherla S, Coulton L, et al (2007) Inhibition of p38alpha mitogen-activated protein kinase prevents the development of osteolytic bone disease, reduces tumor burden, and increases survival in murine models of multiple myeloma. Cancer Res 67:4572-4577. https://doi.org/10.1158/0008-5472.CAN-06-4361

32. Yasui $\mathrm{H}$, Hideshima $\mathrm{T}$, Ikeda $\mathrm{H}$, et al (2007) BIRB 796 enhances cytotoxicity triggered by bortezomib, heat shock protein (Hsp) 90 inhibitor, and dexamethasone via inhibition of p38 mitogen-activated protein kinase/Hsp27 pathway in multiple myeloma cell lines and inhibits paracrine tumour growth. Br J Haematol 136:414-423. https://doi.org/10.1111/j.13652141.2006.06443.x

33. He D, Zhao X, Chen X, et al (2013) BIRB796, the inhibitor of p38 mitogen-activated protein kinase, enhances the efficacy of chemotherapeutic agents in $A B C B 1$ overexpression cells. PloS One 8:e54181. https://doi.org/10.1371/journal.pone.0054181

34. Jin X, Mo Q, Zhang $Y$, et al (2016) The p38 MAPK inhibitor BIRB796 enhances the antitumor effects of VX680 in cervical cancer. Cancer Biol Ther 17:566-576.

https://doi.org/10.1080/15384047.2016.1177676

35. Yeung YT, Yin S, Lu B, et al (2018) Losmapimod Overcomes Gefitinib Resistance in Non-small Cell Lung Cancer by Preventing Tetraploidization. EBioMedicine 28:51-61.

https://doi.org/10.1016/j.ebiom.2018.01.017

36. Schreiber S, Feagan B, D'Haens G, et al (2006) Oral p38 mitogen-activated protein kinase inhibition with BIRB 796 for active Crohn's disease: a randomized, double-blind, placebocontrolled trial. Clin Gastroenterol Hepatol Off Clin Pract J Am Gastroenterol Assoc 4:325-334. https://doi.org/10.1016/j.cgh.2005.11.013

37. Sokol L, Cripe L, Kantarjian H, et al (2013) Randomized, dose-escalation study of the p38 $\alpha$ MAPK inhibitor SCIO-469 in patients with myelodysplastic syndrome. Leukemia 27:977-980. https://doi.org/10.1038/leu.2012.264 
38. Newby LK, Marber MS, Melloni C, et al (2014) Losmapimod, a novel p38 mitogen-activated protein kinase inhibitor, in non-ST-segment elevation myocardial infarction: A randomised phase 2 trial. The Lancet 384:1187-1195. https://doi.org/10.1016/S0140-6736(14)60417-7 


\section{Figure captions}

Figure 1: Treatment scheme during the concurrent phase.

Radiotherapy (RT), Temozolomide (TMZ), pharmacokinetic (PK).

Figure 2: Pharmacokinetic profiles at 100 and $200 \mathrm{mg} / 12 \mathrm{~h}$ on Day 7 of cycle 1

Figure 3: pMAPK-K2 percent inhibition from baseline in PBMCs

Flow cytometry activation of anisomycin-stimulated PBMCs. Paired T-test, $* \mathrm{p}<0.001$ 
Tables :

Table 1: Patient characteristics

\begin{tabular}{|c|c|c|}
\hline Characteristic & Phase $1(n=9)$ & Phase $1+$ Expansion $(n=18)$ \\
\hline Median age (range), years & $59(27-66)$ & $58(27-68)$ \\
\hline \multicolumn{3}{|l|}{ Sex, n (\%) } \\
\hline Male & $2(22)$ & $9(50)$ \\
\hline Female & $7(78)$ & $9(50)$ \\
\hline \multicolumn{3}{|l|}{ RPA class, $\mathrm{n}(\%)$} \\
\hline III & $1(11)$ & $3(17)$ \\
\hline IV & $8(89)$ & $15(83)$ \\
\hline \multicolumn{3}{|c|}{ Karnofsky performance status, $\mathrm{n}(\%)$} \\
\hline 100 & $3(33)$ & $6(33)$ \\
\hline 90 & $2(22)$ & $6(33)$ \\
\hline 80 & $4(45)$ & $5(28)$ \\
\hline 70 & $0(0)$ & $1(6)$ \\
\hline \multicolumn{3}{|l|}{ Extent of primary resection } \\
\hline Gross total resection & $4(44)$ & $6(33)$ \\
\hline Subtotal resection & $5(56)$ & $12(67)$ \\
\hline \multicolumn{3}{|l|}{ Immunohistochemistry } \\
\hline IDH1 mutated & $3(33 \%)$ & $4(22 \%)$ \\
\hline ATRX mutation & $3(33 \%)$ & $4(22 \%)$ \\
\hline p53 (high) & $4(44 \%)$ & $6(33 \%)$ \\
\hline \multicolumn{3}{|l|}{ PTEN expression } \\
\hline Tumor & $1(11 \%)$ & $5(28 \%)$ \\
\hline Endothelial cells & $6(67 \%)$ & $11(61 \%)$ \\
\hline CD34 & $1(11 \%)$ & $4(22 \%)$ \\
\hline pMAPKAP-K2 & $85(10-170)$ & $80(10-170)$ \\
\hline \multicolumn{3}{|l|}{ MGMT methylation } \\
\hline Unmethylated & $2(22 \%)$ & $7(39 \%)$ \\
\hline Methylated & $7(78 \%)$ & $12(67 \%)$ \\
\hline
\end{tabular}


Table 2. Overview of dose-limiting toxicities

\begin{tabular}{|c|c|c|c|c|c|}
\hline Patient $\mathbf{N}^{\circ}$ & $\begin{array}{c}\text { Center } \\
\mathbf{N}^{\circ}\end{array}$ & $\begin{array}{c}\text { Dose level } \\
\text { Ralimetinib }\end{array}$ & Toxicity $\geq 3$ & Timing & Treatment related \\
\hline 4 (phase 1) & 1 & $200 \mathrm{mg} / 12 \mathrm{~h}$ & Gr 3 face edema & Day 13 & Ralimetinib \\
\hline 5 (phase 1$)$ & 3 & $200 \mathrm{mg} / 12 \mathrm{~h}$ & $\begin{array}{l}\text { Gr } 3 \text { rash } \\
\text { Gr } 3 \text { hepatic cytolysis }\end{array}$ & $\begin{array}{l}\text { Day } 11 \\
\text { Day } 30\end{array}$ & $\begin{array}{l}\text { Ralimetinib } \\
\text { TMZ and/or ralimetinib }\end{array}$ \\
\hline 6 (phase 1 ) & 3 & $200 \mathrm{mg} / 12 \mathrm{~h}$ & $\begin{array}{l}\text { Gr } 3 \text { rash } \\
\text { Gr } 3 \text { hepatic cytolysis }\end{array}$ & $\begin{array}{l}\text { Day } 16 \\
\text { Day } 14\end{array}$ & $\begin{array}{l}\text { Ralimetinib } \\
\text { Ralimetinib }\end{array}$ \\
\hline 8 (phase 1 ) & 1 & $100 \mathrm{mg} / 12 \mathrm{~h}$ & Gr 3 lymphopenia & Day 54 & TMZ \\
\hline $\begin{array}{l}10 \\
\text { (expansion) }\end{array}$ & 3 & $100 \mathrm{mg} / 12 \mathrm{~h}$ & $\begin{array}{l}\text { Gr } 4 \text { hepatic cytolysis } \\
\text { Gr } 4 \text { cholestasis }\end{array}$ & $\begin{array}{l}\text { Day } 40 \\
\text { Day } 61\end{array}$ & $\begin{array}{l}\text { TMZ and/or ralimetinib } \\
\text { TMZ }\end{array}$ \\
\hline $\begin{array}{l}11 \\
\text { (expansion) }\end{array}$ & 3 & $100 \mathrm{mg} / 12 \mathrm{~h}$ & Gr 3 hepatic cytolysis & Day 47 & TMZ \\
\hline $\begin{array}{l}16 \\
\text { (expansion) }\end{array}$ & 3 & $100 \mathrm{mg} / 12 \mathrm{~h}$ & Gr 3 rash & Day 12 & Ralimetinib \\
\hline
\end{tabular}


Table 3: All adverse events and grade 3/4 AE

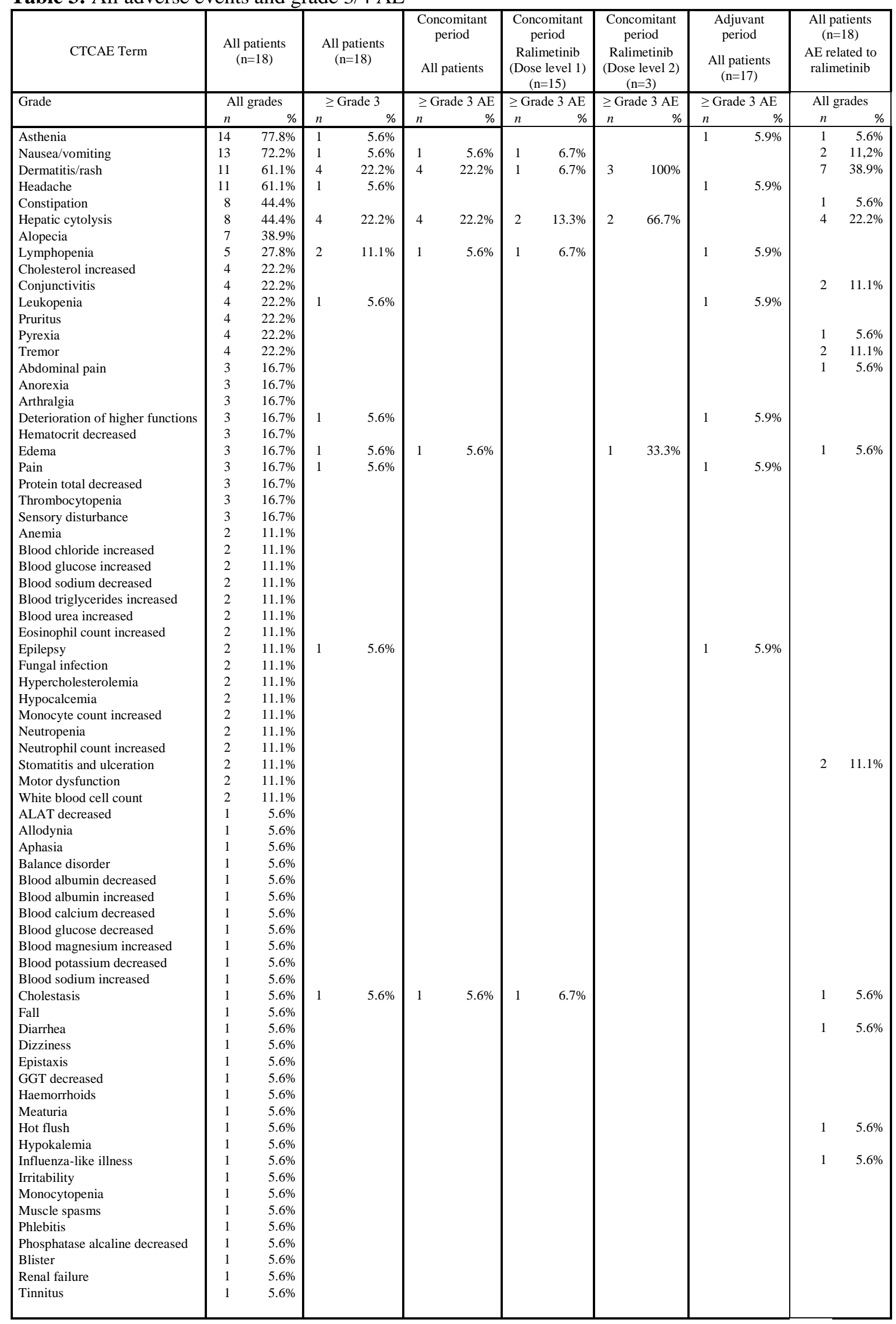


Figure 1

RT $30 * 2 \mathrm{~Gy}, 5 \mathrm{~d} / 7 \mathrm{~d}$

TMZ $75 \mathrm{mg} / \mathrm{m}^{2} / \mathrm{d}^{*} 7 \mathrm{~d}$

Ralimetinib 100 or 200 or $300 \mathrm{mg}$ $/ \mathrm{Q} 12 \mathrm{~h} / \mathrm{d}^{*} 14 \mathrm{~d} / 28 \mathrm{~d}$

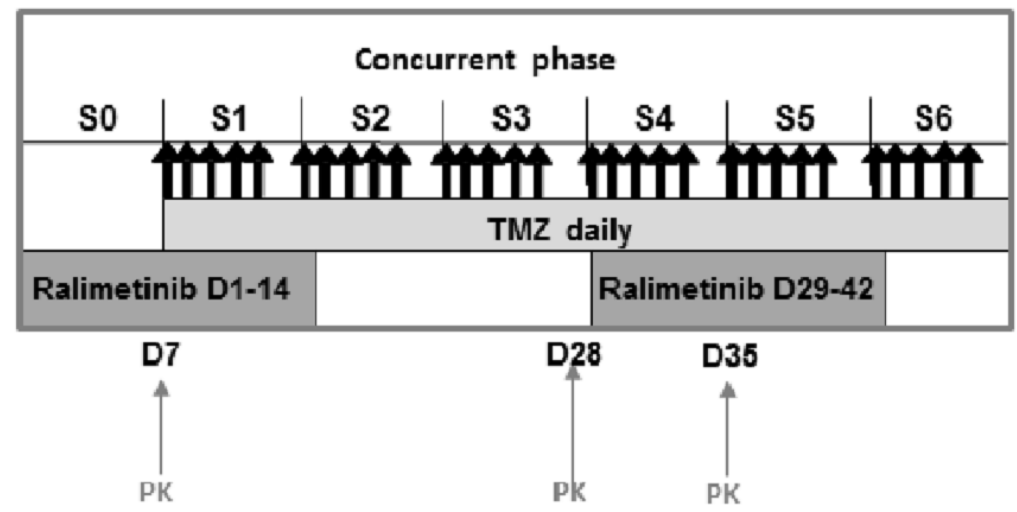

Figure 2 


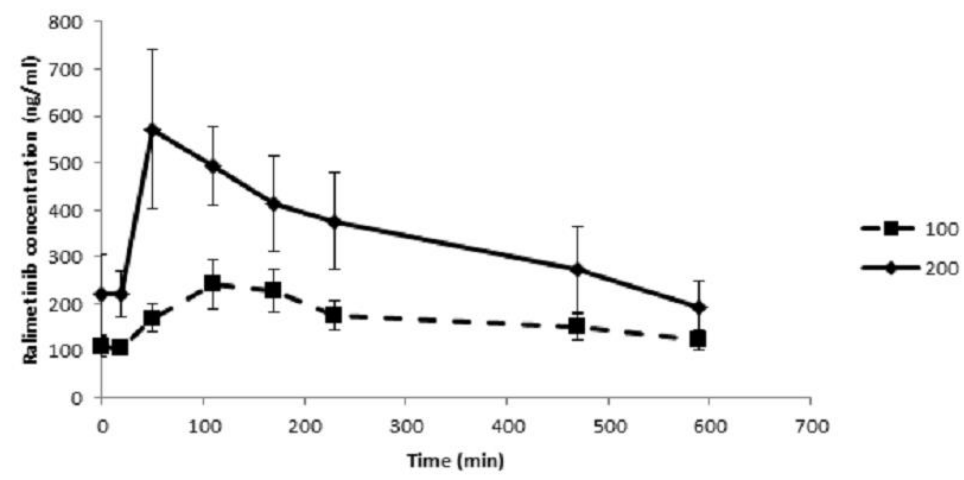


Figure 3

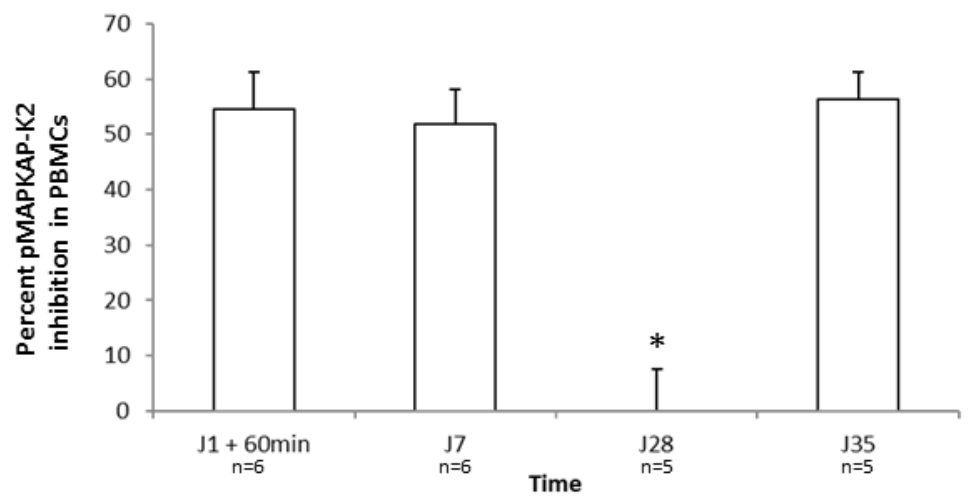

